\title{
Gas-Phase Fragmentation Characteristics of Benzyl-Aminated Lysyl-Containing Tryptic Peptides
}

\author{
Eric S. Simon, Panagiotis G. Papoulias, and Philip C. Andrews \\ Departments of Biological Chemistry, Bioinformatics, and Chemistry, University of Michigan, Ann Arbor, \\ Michigan, USA
}

\begin{abstract}
The fragmentation characteristics of peptides derivatized at the side-chain $\varepsilon$-amino group of lysyl residues via reductive amination with benzaldehyde have been examined using collision-induced dissociation (CID) tandem mass spectrometry. The resulting MS/MS spectra exhibit peaks representing product ions formed from two independent fragmentation pathways. One pathway results in backbone fragmentation and commonly observed sequence ion peaks. The other pathway corresponds to the unsymmetrical, heterolytic cleavage of the $C_{\zeta}-N_{\varepsilon}$ bond that links the benzyl derivative to the side-chain lysyl residue. This results in the elimination of the derivative as a benzylic or tropylium carbocation and a $(n-1)^{+}$-charged peptide product (where $\mathrm{n}$ is the precursor ion charge state). The frequency of occurrence of the elimination pathway increases with increasing charge of the precursor ion. For the benzylmodified tryptic peptides analyzed in this study, peaks representing products from both of these pathways are observed in the MS/MS spectra of doubly-charged precursor ions, but the carbocation elimination pathway occurs almost exclusively for triply-charged precursor ions. The experimental evidence presented herein, combined with molecular orbital calculations, suggests that the elimination pathway is a charge-directed reaction contingent upon protonation of the secondary $\varepsilon$-amino group of the benzyl-derivatized lysyl side chain. If the secondary $\varepsilon$-amine is protonated, the elimination of the carbocation is observed. If the precursor is not protonated at the secondary $\varepsilon$-amine, backbone fragmentation persists. The application of appropriately substituted benzyl analogs may allow for selective control over the relative abundance of product ions generated from the two pathways. (J Am Soc Mass Spectrom 2010, 21, 1624-1632) (C) 2010 American Society for Mass Spectrometry
\end{abstract}

$\mathrm{T}$ The incomplete understanding of the mechanisms involved in the fragmentation of peptides via collision-induced dissociation (CID) remains one of the fundamental limitations in the application of tandem mass spectrometry (MS/MS) to proteomics [1]. Specifically, the inability to predict the relative intensities of sequence product ions produced reduces the confidence of peptide sequence assignments when data from MS/MS spectra are searched against immense lists of in silico peptide sequences generated from proteome databases [2-4]. This represents a barrier to the development of more effective computational tools for accurately assigning peptide sequences to MS/MS spectra as most database search tools are practically limited to treating the formation of all possible product ions with equal probabilities. An improved understanding of the detailed mechanisms involved in peptide fragmentation with CID will directly lead to more effective search tools. Not surprisingly, peptide fragmentation by CID has been studied extensively, and

Address reprint requests to Dr. E. S. Simon, Departments of Biological Chemistry, Bioinformatics, and Chemistry, University of Michigan, $300 \mathrm{~N}$. Ingalls St., Room 1187, Ann Arbor, MI 48109, USA. E-mail: essimon@ umich.edu these efforts have culminated in a number of theoretical models that explain many of the observed fragmentation properties of peptides [1]. One example, the "Pathways in Competition" model [1], is associated with the mobilization of ionizing protons [5] to the amide backbone, competitive cleavages of the amide bonds, and post-cleavage proton transfer and chemical reactions. This model currently represents the most comprehensive description of the mechanism leading to the formation of the commonly observed b- and y-type product ions. However, our understanding of the processes involved in determining the relative abundances of the $\mathrm{b}$ - and y-ions formed remains incomplete.

Breakthroughs relying on some technological advancements and chemical strategies have helped alleviate some of the issues associated with inadequate sequence coverage of peptides via CID. Alternative fragmentation strategies such as electron capture dissociation (ECD) [6] and electron-transfer dissociation (ETD) [7] have been shown to yield MS/MS spectra that provide comprehensive sequence information. ETD has been applied effectively to complement CID to achieve better protein sequence and proteome coverage [8]. The incorporation of chemical modifications onto peptides 
to facilitate sequence interpretation by altering the fragmentation pathways in CID has also been an active area of research. For example, charge derivatization has been applied to facilitate MS/MS spectral interpretation as well as to enhance sensitivity [9]. Among the charge derivatives employed are the quaternary phosphonium [10] and ammonium analogs [11], sulfonic acid [12], and 4-sulfophenyl isothiocyanate [13].

There is also value in other chemical derivatization strategies that induce the enhanced or selective formation of specific product ions that provide useful information about the peptide, including insights into peptide structures or quantification. For example, the isobaric tags for relative and absolute quantification (iTRAQ) modify peptides such that fragmentation yields an array of stable isotope-enriched reporter ions that represent relative quantification along with complimentary sequence ions for identification [14]. Reductive dimethyl labeling of primary amino groups has been shown to enhance the production of $a_{1}$ ions, providing discriminatory information about the Nterminal residue of the peptide [15]. Similarly, amidination of N-termini has been observed to yield the dominant formation of the nearest $\mathrm{N}$-terminal y ion revealing the identity of the N-terminal residue in the peptide [16]. Sulfonium ion-derivatized methionyl peptides exhibit selective fragmentation along the methionyl side chain, producing an exclusive neutral-loss product ion that represents a diagnostic indicator of a methionine residue $[17,18]$. Although the observation of such peaks alone does not constitute a peptide assignment, they can be applied as effective constraints for discriminating sequence candidates from database search results [18]. A variation of the sulfonium ion derivatives has been demonstrated in the form of a cross-linking reagent, which induces selective cleavage along the linker allowing for the peptides to dissociate as intact peptide ions for subsequent independent sequence interrogation with multi-stage tandem mass spectrometry [19]. This demonstrates one case where selective fragmentation is more desirable than comprehensive amide backbone fragmentation.

We present and characterize here the fragmentation characteristics of peptides derivatized at lysyl residues via reductive amination with benzaldehyde (structure displayed in inset of Figure 1) to yield the secondary benzyl amine of the $\varepsilon$-amino group. MS/MS spectra of the derivatized peptides display evidence for two independent fragmentation pathways. One pathway, the $\mathrm{b}_{\mathrm{n}}-\mathrm{y}_{\mathrm{m}}$ pathway, results in backbone fragmentation and commonly observed sequence ion peaks. The b- and y-type product ions are initiated by the transfer of protons to the amide backbone in a process described by the mobile proton model [5]. The other pathway results in the elimination of the benzyl moiety from the derivatized lysyl side chain as a carbocation. In our investigation of this elimination reaction, described here as the carbocation elimination (CCE) pathway, we present evidence that suggests elimination proceeds via

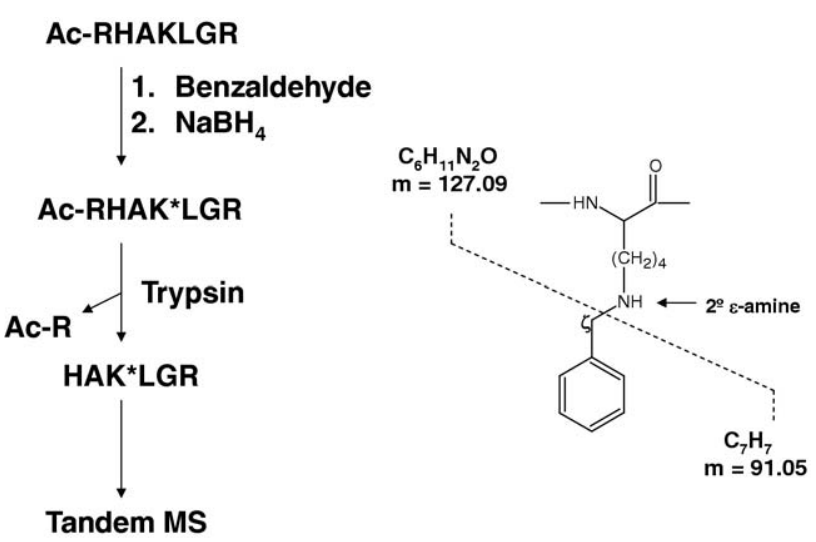

Figure 1. Workflow for the preparation of benzyl-derivatized, tryptic peptides via reductive amination of lysyl residues $\left(\mathrm{K}^{*}\right)$ with benzaldehyde. Inset: Structure of benzyl-aminated lysyl residue.

a charge-directed, unsymmetrical heterolytic cleavage of the $\mathrm{C}_{\zeta}-\mathrm{N}_{\varepsilon}$ bond that links the benzyl derivative to the side-chain lysyl residue forming a benzylic or tropylium carbocation $\left[\mathrm{C}_{7} \mathrm{H}_{7}\right]^{+}$and an intact peptide product ion, and is contingent upon protonation at the secondary $\varepsilon$-amino group of the derivatized lysyl residue. Our results suggest that appropriately substituted benzyl analogs may be employed to control the ratio of product ions formed from the $b_{n}-y_{m}$ and CCE pathways. Such versatility could allow for the incorporation of tags that restrict fragmentation to the selective elimination of the substituted benzyl moiety. Reid and coworkers have already demonstrated the value of restricted fragmentation in the case of cross-linking reagents [19]. On the other hand, the iTRAQ reagent represents a case where a mixture of product ions originating from competing mechanisms can provide both quantitative and qualitative information [14]. Additionally, substitutions that introduce other complimentary properties, such as an affinity property for example, while allowing for the control over relative product ion abundances from competing mechanisms could allow for the enrichment of targeted and selectively tagged subsets of peptides and/or proteins. Finally, suitably substituted benzyl analogs may be designed that introduce predictable product ion mixtures by well-characterized pathways, which allow for studying the fragmentation mechanisms of other competing pathways by probing/ measuring the relative kinetic and thermodynamic factors involved.

\section{Experimental}

\section{Materials}

Unless otherwise stated, all reagents were purchased from Sigma-Aldrich (St. Louis, MO, USA). The Nterminally acetylated peptides used in this study were synthesized by the Protein Structure Facility, part of the Biomedical Research Core Facilities, at the University of Michigan Medical School (Ann Arbor, MI, USA). 


\section{Preparation of Tryptic Peptides Containing} Benzyl-Aminated Lysyl Residues

Peptides $(5 \mu \mathrm{g})$ were dissolved in $100 \mu \mathrm{L}$ of $100 \mathrm{mM}$ triethylammonium bicarbonate $(\mathrm{TEAB}, \mathrm{pH} \sim 8.5)$ with $30 \mathrm{mmol}$ of benzaldehyde. The Schiff bases formed between the aldehydes and the primary amino groups on the peptides were reduced to secondary amines by adding $5 \mu \mathrm{L}$ of $1 \mathrm{M}$ sodium borohydride. The reduction reaction was allowed to proceed undisturbed at room temperature for $45 \mathrm{~min}$ in a fume hood in the dark. The reaction was quenched by adding $1 \mathrm{~mL}$ of $0.1 \%$ trifluoroacetic acid. The reacted peptides were desalted using a Strata-X reversed-phase C18 cartridge obtained from Phenomenex (Torrance, CA, USA) according to the manufacturer's instructions. The desalted peptides were dried and redissolved in $200 \mu \mathrm{L}$ of $100 \mathrm{mM}$ TEAB ( $\mathrm{pH} \sim 8.5)$. $1 \mu \mathrm{g}$ of L-(tosylamido-2-phenyl)ethyl-chloromethylketone treated trypsin, obtained from Worthington Biochemical Corp. (Lakewood, NJ, USA), was added to the peptide solution and incubated at $37^{\circ} \mathrm{C}$ overnight. The digested peptides were desalted as described above, dried to completion, and redissolved in $250 \mu \mathrm{L}$ of $25 \%$ acetonitrile $/ 0.1 \%$ formic acid (vol/vol) for analysis with nanospray ionization tandem mass spectrometry.

\section{Mass Spectrometry}

Peptides were analyzed with a hybrid linear quadrupole ion trap-Orbitrap mass spectrometer (model LTQOrbitrap XL; ThermoFisher Scientific, Inc., San Jose, CA, USA). They were introduced by infusion using a TriVersa Nanomate nanospray ionization source from Advion BioSciences (Ithaca, NY, USA). Peptides were delivered with a pneumatic displacement pressure of $0.45 \mathrm{psi}$ and an applied spray voltage of $1.54 \mathrm{kV}$. The heated capillary temperature was set at $200{ }^{\circ} \mathrm{C}$. Monoisotopic precursor ions were selected for multistage tandem mass spectrometric acquisition using an isolation window of $3.0 \mathrm{~m} / \mathrm{z}$ units and excitation energy settings of 35 for both $\mathrm{MS}^{2}$ and $\mathrm{MS}^{3}$ spectra. All CID spectra were collected in FT (Orbitrap) mode for high mass accuracy (>10 ppm) and peak resolution (30,000 at $\mathrm{m} / \mathrm{z} 400)$.

\section{Computational Methods}

Total energy calculations were performed using density functional theory (DFT) with electron correlations described using the B3LYP hybrid functional. Atomic orbitals were described using the split-valence double- $\zeta$ functions with $d$ and $p$ polarization functions added to both heavier and lighter atoms and diffuse functions added for the heavier atoms [i.e., 6-31+G(d,p)]. The model peptide 2-[(aminoacetyl)amino]-6-(benzylamino)$\mathrm{N}$-methylhexanamide was used for theoretical calculations. Low-energy precursor and product structural conformations were determined at the PM3 semiempirical level of theory followed by further optimiza- tion at the B3LYP level of theory using the 6-31G + $(\mathrm{d}, \mathrm{p})$ basis set. Transition-state barriers were determined by first scanning the potential energy surface at the B3LYP level of theory using the $6-31 G+(d, p)$ basis set. During the scan, the length of the $\mathrm{C}_{\zeta}-\mathrm{N}_{\varepsilon}$ bond (the bond that is cleaved during the elimination reaction) was constrained while allowing all other degrees of freedom to relax. For selected cases the potential energy surface was further explored using QST3. The input structures used for QST3 were those determined from the scan of the potential energy surface. Optimized structures were subjected to harmonic vibrational frequency analysis and visualized using the software package GaussView 3.0. All calculations where done using the Gaussian 2003 molecular modeling software package [20].

\section{Results and Discussion}

\section{Tandem Mass Spectrometry of Multiply-Charged Peptides Derivatized at Lysyl Residues Via Reductive Amination with Benzaldehyde}

As depicted in Figure 1, peptides containing N-terminally acetylated arginine and a single, internal lysyl residue were derivatized via reductive amination with benzaldehyde and then digested with trypsin. This approach allowed for the preparation of tryptic peptides with the modification exclusively on the $\varepsilon$-amino groups of internal lysyl residues leaving the $\mathrm{N}$-termini unmodified (inset Figure 1). The residue mass of the modified lysyl is $218.142 \mathrm{Da}\left(\mathrm{C}_{13} \mathrm{H}_{18} \mathrm{~N}_{2} \mathrm{O}\right)$.

Figure 2a displays the MS/MS spectrum of the doubly-charged precursor ion $\left[\mathrm{MH}_{2}\right]^{2+}$ for the peptide HAK*LGR (where $\mathrm{K}^{*}$ represents a benzyl-aminated lysyl residue). The spectrum exhibits comprehensive sequence information, including a difference of $218 \mathrm{Da}$ between the $\mathrm{y}_{3}$ and $\mathrm{y}_{4}$ ions representing $\mathrm{K}^{*}$. Additionally, the peak annotated as $\left[\left(\mathrm{MH}_{2}\right)^{2+}-\left(\mathrm{C}_{7} \mathrm{H}_{7}\right)^{+}\right]^{+}$ represents a singly-charged product ion corresponding to a loss of a singly-charged moiety of mass 91.05 Da. Based on the elemental composition and mass distribution of $\mathrm{K}^{*}$ (inset Figure 1), this implies cleavage of the $\mathrm{C}_{\zeta}-\mathrm{N}_{\varepsilon}$ bond along the derivatized lysyl side chain releasing a singly-charged benzylic or tropylium carbocation $\left[\mathrm{C}_{7} \mathrm{H}_{7}\right]^{+}$. For simplicity, the elimination of $\left[\mathrm{C}_{7} \mathrm{H}_{7}\right]^{+}$will be referred to as the CCE pathway.

While MS/MS spectra of the doubly-charged precursor ions exhibit a mixture of product ion peaks corresponding to both backbone fragmentation and CCE, MS/MS spectra of triply-charged precursor ions, $\left[\mathrm{MH}_{3}\right]^{3+}$, display peaks representing CCE product ions exclusively (Figure $2 \mathrm{~b}$ ). The base peak represents a doubly-charged product ion $\left[\left(\mathrm{MH}_{3}\right)^{3+}-\left(\mathrm{C}_{7} \mathrm{H}_{7}\right)^{+}\right]^{2+}$ corresponding to the loss of a singly-charged moiety of mass $91.05 \mathrm{Da}$, again implying the loss of the singlycharged benzylic or tropylium carbocation $\left[\mathrm{C}_{7} \mathrm{H}_{7}\right]^{+}$ from the lysyl side chain. The other peak $(\mathrm{m} / \mathrm{z}$ 91.05) displayed in the MS/MS spectrum of the triply-charged 
(a)

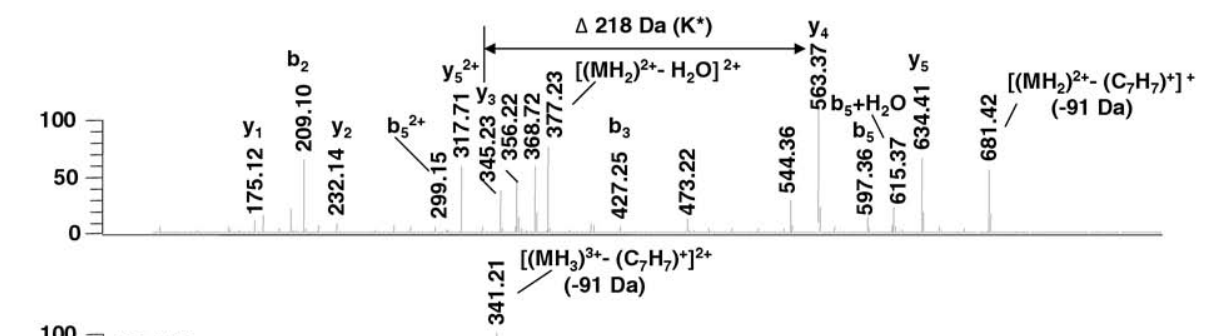

(b)
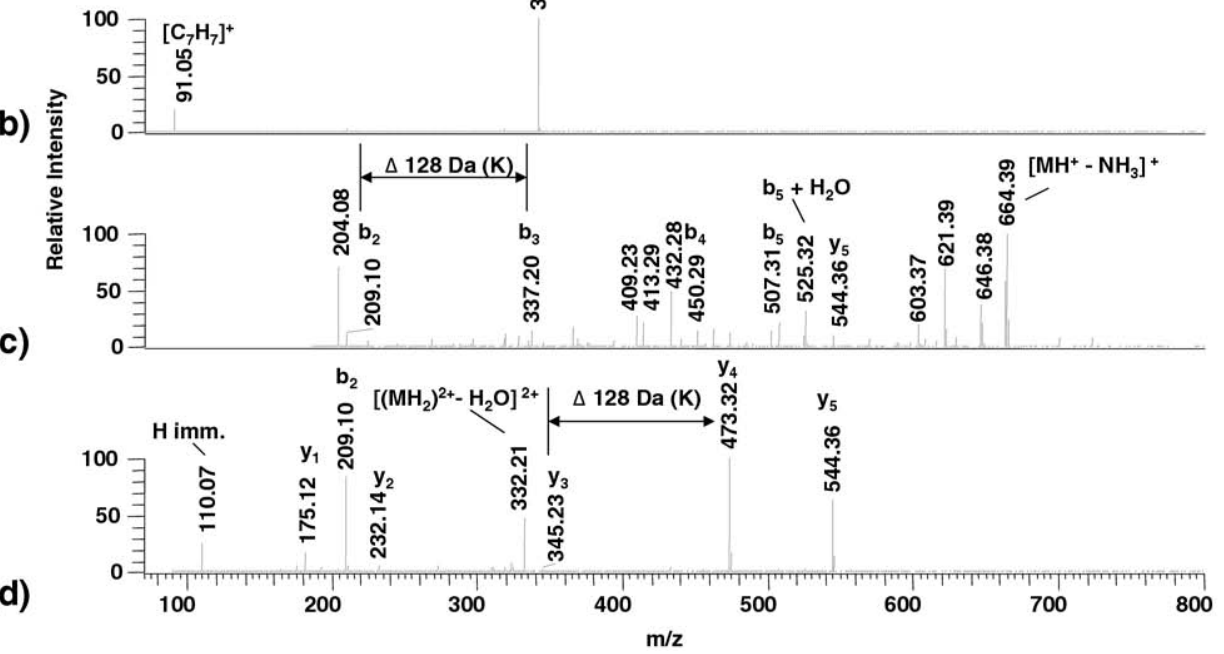

Figure 2. CID tandem mass spectra of the benzyl-derivatized peptide HAK*LGR (where $K^{*}$ represents the benzyl-aminated lysyl residue). (a) CID MS/MS product ion spectrum of the doubly-charged $\left[\mathrm{MH}_{2}\right]^{2+}$ precursor ion. (b) CID MS/MS product ion spectrum of the triply-charged $\left[\mathrm{MH}_{3}\right]^{3+}$ precursor ion. (c) CID MS ${ }^{3}$ product ion spectrum of the $\left[\left(\mathrm{MH}_{2}\right)^{2+}-\left(\mathrm{C}_{7} \mathrm{H}_{7}\right)^{+}\right]^{+}$from Figure 2a. (d) CID MS $\mathrm{M}^{3}$ product ion spectrum of the $\left[\left(\mathrm{MH}_{3}\right)^{3+}-\left(\mathrm{C}_{7} \mathrm{H}_{7}\right)^{+}\right]^{2+}$ from Figure $2 \mathrm{~b}$.

precursor ion (Figure $2 \mathrm{~b}$ ) represents the dissociated benzylic or tropylium carbocation $\left[\mathrm{C}_{7} \mathrm{H}_{7}\right]^{+}$from the precursor. The characteristic lower one-third $\mathrm{m} / \mathrm{z}$ omission of product ions in tandem MS scans in ion trap mass spectrometers prohibited the detection of the $\left[\mathrm{C}_{7} \mathrm{H}_{7}\right]^{+}$product ion from the doubly-charged precursor ion (Figure 2a).

\section{Hypothesis: Carbocation Elimination Pathway is a} Charge-Directed Mechanism and Contingent Upon Protonation at the Secondary $\varepsilon$-Amino Group of the Benzyl-aminated Lysyl Residue

Key factors involved in the mechanism of the CCE pathway can be extracted from the tandem mass spectra displayed in Figure 2. Considering the structure of the benzyl-aminated lysyl residue (Figure 1) and that the elimination reaction results in a loss of a singly-charged ion of mass $91.05 \mathrm{Da}$, it can be asserted that the benzyl moiety dissociates as a $\left[\mathrm{C}_{7} \mathrm{H}_{7}\right]^{+}$benzylic or tropylium carbocation [21]. These aromatic product ions are effective leaving groups that are highly stable owing to resonance delocalization of the positive charge. Contrasting features of the MS/MS spectra of the doublyand triply-charged precursor ions (Figure 2a and b, respectively) combine to suggest that initiation of the CCE pathway is contingent upon protonation of the secondary $\varepsilon$-amino group (forming a dialkyl ammo- nium ion) on the side chain of the benzyl-derivatized lysyl residue. This can be rationalized from the observation that doubly-charged precursors yield CCE products along with a series of sequence ion products (Figure 2a), while triply-charged precursors yield CCE products exclusively (Figure 2b). Considering first the triply-charged precursors, all feasible basic sites on the peptide HAK*LGR would be protonated, assuming that protonation at either the $\mathrm{N}$-terminal primary amino group or the histidinyl imidazole excludes the other as a possible charged site due to proximity. Between these two sites, protonation of the imidazole would be more likely due to its higher gas-phase proton affinity relative to the primary amino group [22]. The other two sites of protonation would be the C-terminal guanidinium and the secondary $\varepsilon$-amino group of the benzylaminated lysyl side chain. Not all of the sites would be protonated in the case of the doubly-charged precursors. They would exist as a distribution of doublycharged isomers, where one proton would be sequestered at the C-terminal guanidinium and the other proton partitioned between the secondary $\varepsilon$-amino group and the $\mathrm{N}$-terminus (either the imidazole or primary amino group). Although other factors could be involved that determine where the ionizing protons reside (e.g., steric effects, charge solvation, and Coulombic effects), similar proton affinities between the $\mathrm{N}$-terminal imidazole and the secondary $\varepsilon$-amino group 
suggest a fairly equal population of ions protonated at both sites [22, 23]. We hypothesize, as illustrated in Scheme 1, that isomers protonated at the secondary $\varepsilon$-amino group can fragment via the CCE pathway through a charge-directed mechanism (eliminating $\left[\mathrm{C}_{7} \mathrm{H}_{7}\right]^{+}$), while amide backbone fragmentation persists for isomers not protonated at that site. This is drawn from the observation that triply-charged precursors, where all ions are most assuredly protonated at the secondary $\varepsilon$-amino group, fragment via the CCE pathway exclusively. On the other hand, not all copies of the doubly-charged precursors would be expected to carry a proton on the derivatized lysyl side chain and, consequently, not all doubly-charged precursors yield CCE products.

$\mathrm{MS}^{3}$ spectra of the $\left[\left(\mathrm{MH}_{2}\right)^{2+}-\left(\mathrm{C}_{7} \mathrm{H}_{7}\right)^{+}\right]^{+}$and $\left[\left(\mathrm{MH}_{3}\right)^{3+}-\left(\mathrm{C}_{7} \mathrm{H}_{7}\right)^{+}\right]^{2+}$ peptide product ions provide further support for the requirement of protonation at the secondary $\varepsilon$-amino group for initiating the CCE pathway (Figure 2c and d, respectively). The $m / z$ values for these product ions (681.42 and 341.21, respectively) match the theoretical $\mathrm{m} / \mathrm{z}$ values of the unmodified peptide HAKLGR as singly and doubly-protonated peptide ions. This implies that the lysyl residue reclaims its usual primary $\varepsilon$-amino group structure after elimination of the carbocation. This implication is supported by the $\mathrm{MS}^{3}$ spectra of the $\left[\left(\mathrm{MH}_{2}\right)^{2+}-\left(\mathrm{C}_{7} \mathrm{H}_{7}\right)^{+}\right]^{+}$and $\left[\left(\mathrm{MH}_{3}\right)^{3+}-\left(\mathrm{C}_{7} \mathrm{H}_{7}\right)^{+}\right]^{2+}$ product ions (Figure $2 \mathrm{c}$ and $\mathrm{d}$, respectively), where the mass differences of $128 \mathrm{Da}$ correspond to unmodified lysyl residues. A likely explanation for the lysyl residue regaining its primary $\varepsilon$-amino structure after dissociation of the $\left[\mathrm{C}_{7} \mathrm{H}_{7}\right]^{+}$ion is that the secondary $\varepsilon$-amino group of the precursor ion is protonated before activation. Heterolytic cleavage of the $\mathrm{C}_{\zeta}-\mathrm{N}_{\varepsilon}$ bond could then yield the primary amino group (e.g., $\left[\mathrm{R}-\mathrm{NH}_{2}{ }^{+}-\mathrm{C}_{7} \mathrm{H}_{7}\right]^{+} \rightarrow \mathrm{R}-\mathrm{NH}_{2}+$ $\left.\left[\mathrm{C}_{7} \mathrm{H}_{7}\right]^{+}\right)$.

Considering the interpretation of the data discussed above, the CCE pathway could be described as a charge-directed elimination reaction that proceeds via an unsymmetrical, heterolytic cleavage of the $\mathrm{C}_{\zeta}-\mathrm{N}_{\varepsilon}$ bond resulting in the dissociation of a benzylic or tropylium carbocation from the remaining intact peptide product (Scheme 1). This reaction accounts for the observations described above for the spectra shown in Figure 2, including the loss of a singly charged ion of mass $91 \mathrm{Da},\left[\mathrm{C}_{7} \mathrm{H}_{7}\right]^{+}$, from the precursor ion, the requirement of protonation at the secondary $\varepsilon$-amino group of the derivatized lysyl residue to initiate the elimination reaction, and the lysyl residue in the peptide product ion $\left[\left(\mathrm{MH}_{2}\right)^{2+}-\left(\mathrm{C}_{7} \mathrm{H}_{7}\right)^{+}\right]^{+}$reclaiming its primary $\varepsilon$-amino group structure. Precedence for this type of gas-phase fragmentation reaction was established and characterized via tandem mass spectrometric and theoretical studies of protonated alkylammonium $[24,25]$ and $N$-benzylpyridinium cations [21, 26]. In those studies, competing fragmentation pathways were observed yielding either a neutral amine and carbocation or, alternatively, an ammonium ion and an alkene [25]. For $N$-benzylammonium analogs, formation of a neutral amine and a benzylic or tropylium carbocation $\left[\mathrm{C}_{7} \mathrm{H}_{7}\right]^{+}$was observed exclusively [21]. Dissociation of the carbocation was determined to proceed via "loose complexes" formed between an incipient cation coordinated to the developing amine [24]. Our results show that this fragmentation behavior is preserved on protonated $\mathrm{N}$-benzyl-aminated peptides with the observed dissociation of $\left[\mathrm{C}_{7} \mathrm{H}_{7}\right]^{+}$yielding the neutral primary $\varepsilon$-amino group on the side chain of the lysyl residue as described in Scheme $\mathbf{1 .}$

Spectra of other benzyl-aminated peptides are displayed in Supplemental Figures 1S-4S, which can be found in the electronic version of this article. The MS/MS spectrum of the triply-charged precursor ion of the peptide IGK*GVAR (Figure $1 \mathrm{Sb}$ ) displays a product ion peak for a sequence ion $\left(\mathrm{y}_{6}{ }^{2+}\right)$ representing the only case in this study where a triply-charged precursor ion did not yield products of the CCE pathway exclusively, although this pathway was still dominant. This observation suggests that while a precondition of the CCE pathway may be protonation of the secondary $\varepsilon$-amino group of the derivatized lysyl residue, this does not

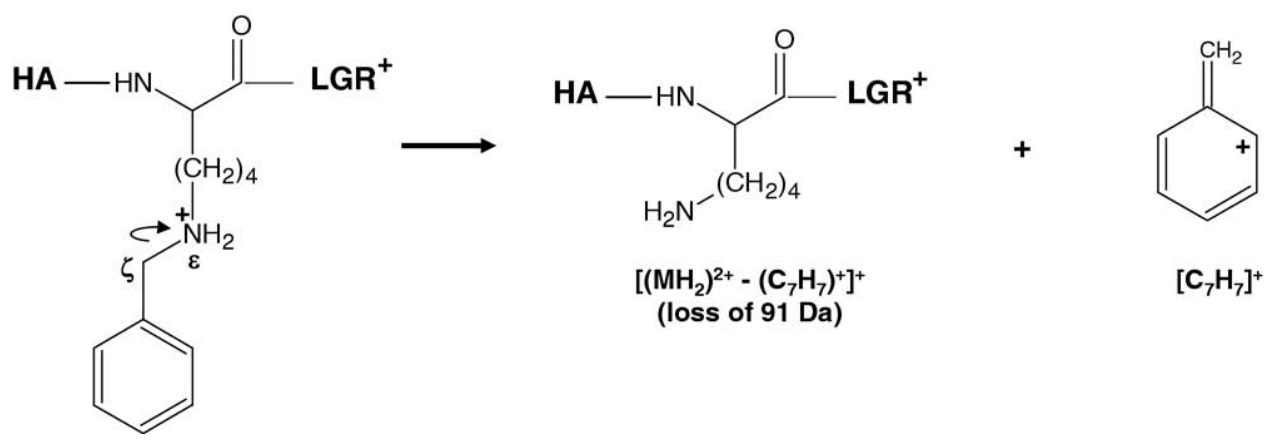

Scheme 1. The CCE pathway. Proposed as a charge-directed elimination reaction contingent upon protonation of the secondary $\varepsilon$-amino group and proceeds via an unsymmetrical, heterolytic cleavage of the $\mathrm{C}_{\zeta}-\mathrm{N}_{\varepsilon}$ bond resulting in the dissociation of a benzylic or tropylium carbocation, $\left[\mathrm{C}_{7} \mathrm{H}_{7}\right]^{+}, \mathrm{from}$ the remaining intact peptide product ion $\left[\left(\mathrm{MH}_{2}\right)^{2+}-\left(\mathrm{C}_{7} \mathrm{H}_{7}\right)^{+}\right]^{+}$. For simplicity, only the benzylic cation is displayed as a product. 


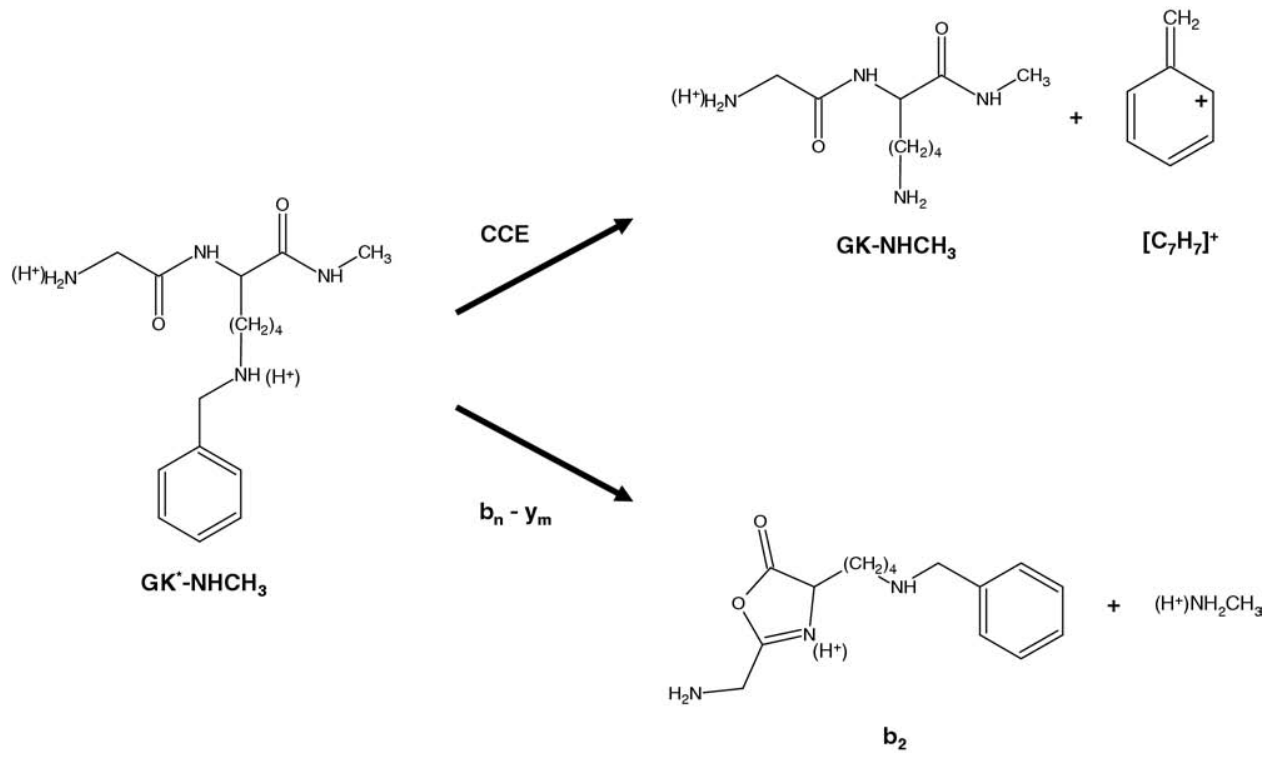

Scheme 2. Precursor ion structure of the model peptide 2-[(aminoacetyl)amino]-6-(benzylamino)- $N$ methylhexanamide (labeled $\mathrm{GK}^{*}-\mathrm{NHCH}_{3}$ ) and corresponding product structures resulting from the CCE pathway and the $b_{n}-y_{m}$ pathway used for calculating the transition-state barriers for the CCE pathway and comparing the theoretical relative reaction energies of the two pathways.

preclude completely the formation of amide backbone fragmentation products. Certain conditions may exist (e.g., amino acid composition) where backbone fragmentation may be competitive with CCE even when the secondary $\varepsilon$-amino group is protonated. In other words, possible competition may exist for the proton at secondary $\varepsilon$-amino group either initiating the CCE pathway or becoming "mobile" and activating backbone cleavage.

\section{Structural Examination of a Simple Benzyl- Aminated Peptide Model and Comparison of the Transition State Barriers and Relative Reaction Energies for the CCE Pathway Versus Amide Backbone Fragmentation}

Based upon our observations and interpretation of tandem mass spectra of benzyl-aminated peptides (discussed above), we hypothesized that the CCE pathway is contingent upon protonation of the secondary $\varepsilon$-amino group of the derivatized lysyl residue. To gain more insight into this, a series of molecular orbital calculations were performed on a simple benzylaminated peptide model (2-[(aminoacetyl)amino]-6(benzylamino)- $\mathrm{N}$-methylhexanamide) (displayed and labeled as $\mathrm{GK}^{*}-\mathrm{NHCH}_{3}$ in Scheme 2). Using this peptide model, we performed molecular orbital calculations to determine the following: (1) low-energy structures of the precursor in two charge states $(+1$ and +2$)$ allowing us to assess the effect of protonation at the secondary $\varepsilon$-amino group on the $\mathrm{C}_{\zeta}-\mathrm{N}_{\varepsilon}$ bond length. For the +1 charge state, two protonation sites were examined. (2) An estimation of the reaction energy for the CCE pathway leading to the products displayed in Scheme 2 for comparison against the reaction energy associated with an amide bond cleavage reaction (also displayed in Scheme 2). (3) An estimation of the activation energy barrier of the CCE pathway for comparison against the barriers associated with the $b_{n}-y_{m}$ pathway calculated previously for simple peptides and reported in the literature. The protons $\left(\mathrm{H}^{+}\right)$on the precursor structure (as well as the product structures) in Scheme 2 represent sites that were considered as protonated or unprotonated for the respective calculations. The charge states of the precursor that were considered include: (1) protonation at the secondary $\varepsilon$-amino group of benzyl-aminated lysyl residue $\left[\mathrm{GK}^{*}\left(\mathrm{H}^{+}\right)-\mathrm{NHCH}_{3}\right]$, (2) protonation at the $\mathrm{N}$-terminal amino group $\left[\left(\mathrm{H}^{+}\right) \mathrm{GK}^{*}-\mathrm{NHCH}_{3}\right]$, and (3) protonation at both sites $\left[\left(\mathrm{H}^{+}\right) \mathrm{GK}^{*}\left(\mathrm{H}^{+}\right)-\mathrm{NHCH}_{3}\right]$. Low-energy precursor and product structures were determined initially at the PM3 level of theory and low-energy conformers were further optimized at the B3LYP/6-31 + G (d,p) level of theory. The optimized precursor structures are displayed in Figure 5S.

Among other data, Table 1 displays the total energies of the three protonated forms of the precursor model peptide as well as the length of the $C_{\zeta}-\mathrm{N}_{\varepsilon}$ bond for each. In the cases where the model is protonated at the secondary $\varepsilon$-amino group of $\mathrm{K}^{*},\left[\mathrm{GK}^{*}\left(\mathrm{H}^{+}\right)-\mathrm{NHCH}_{3}\right]$ and $\left[\left(\mathrm{H}^{+}\right) \mathrm{GK}^{*}\left(\mathrm{H}^{+}\right)-\mathrm{NHCH}_{3}\right]$, the $\mathrm{C}_{\zeta}-\mathrm{N}_{\varepsilon}$ bond is lengthened (1.52 $\AA$ and $1.54 \AA$, respectively), suggesting a weaker bond that is more susceptible to cleavage compared with the case where the secondary $\varepsilon$-amino group is not protonated. This is consistent with protonation at the secondary $\varepsilon$-amino group of $\mathrm{K}^{*}$ being essential to the CCE pathway. The precursor energies in Table 1 also indicate that protonation at the secondary amino group, $\left[\mathrm{GK}^{*}\left(\mathrm{H}^{+}\right)-\mathrm{NHCH}_{3}\right.$ ], is $\sim 11.5 \mathrm{kcal} / \mathrm{mol}$ 


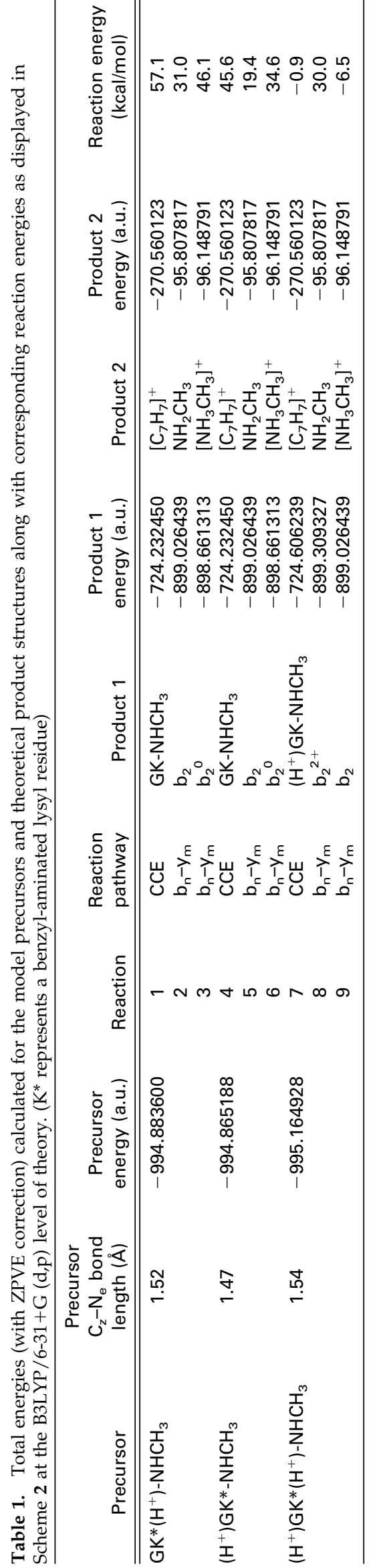

more favorable than protonation at the N-terminal primary amine, $\left[\left(\mathrm{H}^{+}\right) \mathrm{GK}^{*}-\mathrm{NHCH}_{3}\right]$. The reaction energies in Table 1 simply represent the difference in total energies of products versus reactants for each reaction. It is worthwhile noting that the CCE reaction is endothermic for the singly-charged precursors (reactions 1 and 4 in Table 1, respectively) but becomes exothermic when the precursor is doubly-charged (reaction 7). The increased thermodynamic favorability coincides with our experimental observations that the products of the CCE pathway are observed more prominently, in fact in most cases, exclusively, at the higher precursor charge state (see Figure 2a and b, and Figures 1S-4S). It should also be noted that for simplicity, the total energies listed for $\left[\mathrm{C}_{7} \mathrm{H}_{7}\right]^{+}$in Table 1 correspond only to the benzylic cation. Our exclusion of the tropylium cation in this case is based upon a previous report that the dissociation of unsubstituted benzylpyridinium ions dissociate by direct cleavage forming only the benzylic cation [27]. For comparison, Table 1 also includes reaction energies (reactions 2, 3, 5, 6, 8, and 9) corresponding to possible products formed by amide bond cleavage via the $b_{n}-y_{m}$ pathway (Scheme 2 ) from each precursor. In Scheme 2 and Table $1, b_{2}$ represents a protonated oxazolone and $\mathrm{b}_{2}{ }^{0}$ represents a neutral oxazolone structure. Like the CCE pathway, the formation of amide cleavage products from the singly-charged precursor is endothermic but becomes an exothermic reaction when the precursor is doubly-charged (reaction 9) with exception to the case that $\mathrm{a} \mathrm{b}_{2}{ }^{2+}$ ion is formed (reaction 8). Generally, the $b_{n}-y_{m}$ pathway appears to be more thermodynamically favorable than the CCE pathway but little can be drawn from these calculations directly without considering the transition-state activation barriers.

Activation barriers for amide bond cleavage reactions have been estimated for several simple peptides and will be referred to in comparison to the CCE pathway activation barriers determined in this study for the model peptide $\mathrm{GK}^{*}-\mathrm{NHCH}_{3}$. The previously calculated $b_{n}-y_{m}$ transition-state barriers for the peptides listed in Table 2 generally range from 30 to 40 $\mathrm{kcal} / \mathrm{mol}$ relative to the precursor minimum [28-30]. The barriers for the more basic lysine-containing dipeptides KG [28] and VK [29] are higher than non-basic peptides like pentaalanine [30] since protons on the $\varepsilon$-amino group of the lysyl side chains are less mobile than protons on the amino group of the $\mathrm{N}$-terminus. Table 2 also lists the transition-state barriers associated with cleavage of the $\mathrm{C}_{\zeta}-\mathrm{N}_{\varepsilon}$ bond for the model GK*$\mathrm{NHCH}_{3}$ in the two singly-charged cases considered in this study. Only singly-protonated peptides of GK*$\mathrm{NHCH}_{3}$ were examined for comparison against the barriers calculated in the previous studies on singlyprotonated KG [28], VK [29], and pentaallanine [30] peptides. When protonated at the secondary $\varepsilon$-amino group of the derivatized lysyl residue $\left[\mathrm{GK}^{*}\left(\mathrm{H}^{+}\right)-\right.$ $\mathrm{NHCH}_{3}$, our theoretical estimation of the activation barrier is $42.1 \mathrm{kcal} / \mathrm{mol}$. For the singly-charged isomer protonated at the $\mathrm{N}$-terminal primary amino group 
Table 2. Transition state (TS) activation barriers determined in previous studies for simple peptides dissociating via amide cleavage reactions $\left(\mathrm{a}_{1}-\mathrm{y}_{1}, \mathrm{~b}_{1}\right.$-ion formation, and $\mathrm{b}_{\mathrm{n}}-\mathrm{y}_{\mathrm{m}}$ pathways) and benzyl-aminated model peptide $\mathrm{GK}^{*}-\mathrm{NHCH}_{3}$ (displayed in Scheme 2 ) dissociating via the CCE pathway

\begin{tabular}{|c|c|c|c|c|c|}
\hline Precursor & Pathway & Product 1 & Product 2 & $\mathrm{TS}(\mathrm{kcal} / \mathrm{mol})$ & Reference \\
\hline KG & $b_{1}$-lon formation & $\alpha$-Amino- $\varepsilon$-caprolactam & Gly & 39.4 & {$[28]$} \\
\hline VK & $a_{1}-y_{1}$ & $a_{1}$ & $y_{1}$ & 43.7 & [29] \\
\hline VN & $a_{1}-y_{1}$ & $a_{1}$ & $y_{1}$ & 37.2 & [29] \\
\hline VQ & $a_{1}-y_{1}$ & $a_{1}$ & $\mathrm{y}_{1}$ & 38.3 & [29] \\
\hline AAAAA & $b_{2}-y_{3}$ & $b_{2}$ & $y_{3}$ & 32.7 & [30] \\
\hline AAAAA & $b_{3}-y_{2}$ & $b_{3}$ & $y_{2}$ & 31.9 & [30] \\
\hline AAAAA & $b_{4}-y_{1}$ & $b_{4}$ & $\mathrm{y}_{1}$ & 29.4 & {$[30]$} \\
\hline $\mathrm{GK}^{*}\left(\mathrm{H}^{+}\right)-\mathrm{NHCH}_{3}$ & CCE & GK-NHCH 3 & {$\left[\mathrm{C}_{7} \mathrm{H}_{7}\right]^{+}$} & 42.1 & * \\
\hline$\left(\mathrm{H}^{+}\right) \mathrm{GK}^{*}-\mathrm{NHCH}_{3}$ & CCE & $\mathrm{GK}-\mathrm{NHCH}_{3}$ & {$\left[\mathrm{C}_{7} \mathrm{H}_{7}\right]^{+}$} & 79.5 & * \\
\hline
\end{tabular}

*Determined computationally in the present study.

$\left[\left(\mathrm{H}^{+}\right) \mathrm{GK}^{*}-\mathrm{NHCH}_{3}\right]$, the barrier is significantly higher at $79.5 \mathrm{kcal} / \mathrm{mol}$. This supports the hypothesis that the CCE pathway is favored when the derivatized precursor is protonated at the secondary $\varepsilon$-amino group.

For the model protonated at the secondary $\varepsilon$-amino group, $\left[\mathrm{GK}^{*}\left(\mathrm{H}^{+}\right)-\mathrm{NHCH}_{3}\right]$, the estimated activation barrier for dissociation via the CCE pathway (42.1 $\mathrm{kcal} / \mathrm{mol}$ ) is similar to those determined for amide cleavage reactions originating from the singly-charged lysine-containing dipeptides KG and VK (Table 2). This suggests that for simple peptides like the model GK$\mathrm{NHCH}_{3}$, singly-charged precursors protonated at the secondary $\varepsilon$-amino group can fragment competitively either by the $b_{n}-y_{m}$ or CCE pathways. However, another point to consider is that a secondary amino group typically has a higher gas-phase proton affinity [23] than primary amino groups. This implies that a greater distribution of ions could be protonated on the derivatized side chain compared with peptides containing unmodified lysyl residues and also suggests that more energy may be required to mobilize a proton from the secondary $\varepsilon$-amino group thus favoring the CCE pathway over the $b_{n}-y_{m}$ pathway. With these factors in mind, it can be conjectured that at lower precursor charge states, copies protonated at the secondary $\varepsilon$-amino group of the derivatized lysyl residue could conceivably fragment by either pathway but a higher occurrence of the CCE pathway may be more likely. The majority of the sequence ions formed (Figure 2a) are likely to originate predominantly from precursors protonated at the $\mathrm{N}$-terminal primary amino group. At higher charge states, the CCE pathway occurs almost exclusively as indicated by the lack of sequence ion peaks observed (Figure 2b) and reflects the greater population of precursor ions likely protonated at the secondary $\varepsilon$-amino group.

\section{Conclusions}

This report describes the investigation of the fragmentation characteristics for tryptic peptides containing internally benzyl-aminated lysyl residues using CID tandem mass spectrometry. Two fragmentation path- ways were observed; the $b_{n}-y_{m}$ pathway yielding sequence ions and the CCE pathway leading to side-chain cleavage of the derivatized lysyl residue forming a benzylic or tropylium carbocation and a $(n-1)^{+}-$ charged peptide product (where $\mathrm{n}$ is the precursor ion charge state). The favored pathway appears to be dependent upon the charge status of the secondary $\varepsilon$-amino group of the derivatized lysyl residue. Evidence described herein suggests that protonation of the secondary $\varepsilon$-amino group, forming an alkylammonium ion, activates the CCE pathway. Otherwise, backbone cleavage occurs via proton mobilization. As a result, the CCE pathway becomes more predominant at higher precursor ion charge states. In effect, the secondary benzylamine moiety is acting to switch the fragmentation pathway from amide backbone fragmentation to CCE.

Despite considerable research and progress in understanding the mechanism of proton mobilization, a model that accurately predicts the distribution of product ion abundances remains elusive. This represents a barrier against the development of more advanced bioinformatics tools. Chemical derivatization strategies that induce predictable fragmentation events could contribute to our understanding of CID mechanisms and might also lead to alternative strategies for peptide structure elucidation. Peptide modification schemes that produce benzyl-aminated structures (or related chemical moieties tuned to cause directed fragmentation) represent a versatile approach to inducing a mixture of product ions that suit a specific application in global or targeted proteomics. The results reported here suggest that the relative yield of sequence ions versus CCE product ions can be influenced by strategic incorporation of substituents on the benzyl ring, which affect the proton affinity of the secondary $\varepsilon$-amino group.

\section{Acknowledgments}

The authors acknowledge support for this research by the NCRR (P41 RR018627) to P.C.A. The authors thank Wayne State University for access to their computational grid and the Charles Brooks 
research group in the University of Michigan Chemistry Department for access to their computer cluster.

\section{Appendix A Supplementary Material}

Supplementary material associated with this article may be found in the online version at doi:10.1016/ j.jasms.2010.04.006.

\section{References}

1. Paizs, B.; Suhai, S. Fragmentation Pathways of Protonated Peptides. Mass Spectrom. Rev. 2005, 24, 508-548.

2. Aebersold, R.; Mann, M. Mass Spectrometry-Based Proteomics. Nature 2003, 422, 198-207.

3. Aebersold, R.; Goodlett, D. R. Mass Spectrometry in Proteomics. Chem. Rev. 2001, 101, 269-295.

4. Wielsch, N.; Thomas, H.; Surendranath, V.; Waridel, P.; Frank, A.; Pevzner, P.; Shevchenko, A. Rapid Validation of Protein Identifications with the Borderline Statistical Confidence Via De Novo Sequencing and MS BLAST Searches. J. Proteome Res. 2006, 5, 2448-2456.

5. Wysocki, V. H.; Tsaprailis, G.; Smith, L. L.; Breci, L. A. Mobile and Localized Protons: A Framework for Understanding Peptide Dissociation. J. Mass Spectrom. 2000, 35, 1399-1406.

6. Zubarev, R. A.; Kelleher, N. L.; McLafferty, F. W. Electron Capture Dissociation of Multiply Charged Protein Cations. A Nonergodic Process. I. Am. Chem. Soc. 1998, 120, 3265-3266.

7. Syka, J. E. P.; Coon, J. J.; Schroeder, M. J.; Shabanowitz, J.; Hunt, D. F. Peptide and Protein Sequence Analysis by Electron Transfer Dissociation Mass Spectrometry. Proc. Natl. Acad. Sci. U.S.A. 2004, 101, 95289533.

8. Good, D. M.; Wirtala, M.; McAllister, G. C.; Coon, J. J. Performance Characteristics of Electron Transfer Dissociation Mass Spectrometry. Mol. Cell. Proteom. 2007, 6, 1942-1951.

9. Roth, K. D. W.; Huang, Z.; Sadagopan, N.; Watson, J. T. Charge Derivatization of Peptides for Analysis by Mass Spectrometry. Mass Spectrom. Rev. 1998, 17, 255-274.

10. Wagner, D. S.; Salari, A.; Gage, D. A.; Leykam, J.; Fetter, J.; Hollingsworth, R.; Watson, J. T. Derivatization of Peptides to Enhance Ionization Efficiency and Control Fragmentation During Analysis by Fast Atom Bombardment Tandem Mass Spectrometry. Biol. Mass Spectrom. 1991, 20, 419-425.

11. Stults, J. T.; Lai, J.; McCune, S.; Wetzel, R. Simplification of High-Energy Collision Spectra of Peptides by Amino-Terminal Derivatization. Anal. Chem. 1993, 65, 1703-1708.

12. Keough, T.; Youngquist, R. S.; Lacey, M. P. Sulfonic Acid Derivatives for Peptide Sequencing by MALDI MS. Anal. Chem. 2003, 75, 156A-165A.

13. Marekov, L. N.; Steinert, P. M. Charge Derivatization by 4-Sulfophenyl Isothiocyanate Enhances Peptide Sequencing by Post-Source Decay Matrix-Assisted Laser Desorption/Ionization Mass Spectrometry. I. Mass Spectrom. 2003, 38, 373-377.

14. Ross, P.L.; Huang, Y. N.; Marchese, J. N.; Williamson, B.; Parker, K.; Hattan, S.; Khainovski, N.; Pillai, S.; Dey, S.; Daniels, S.; Purkayastha, S.; Juhasz, P.; Martin, S.; Bartlet-Jones, M.; He, F.; Jacobson, A.; Pappin, D. J. Mulitplexed Protein Quantitation in Saccharomyces cerevisiae Using Amine-Reactive Isobaric Tagging Reagents. Mol. Cell. Proteom. 2004, 3, 1154-1169.
15. Hsu, J.; Huang, S.; Shiea, J.; Huang, W.; Chen, S. Beyond Quantitative Proteomics: Signal Enhancement of the $\mathrm{a}_{1}$ Ion as a Mass Tag for Peptide Sequencing Using Dimethyl Labeling. J. Proteome Res. 2005, 4, 101-108. 16. Beardsley, R. L.; Reilly, J. P. Fragmentation of Amidinated Peptide Ions. J. Am. Soc. Mass Spectrom. 2004, 15, 158-167.

17. Amunugama, M.; Roberts, K. D.; Reid, G. E. Mechanisms for the Selective Gas-Phase Fragmentation Reactions of Methionine Side Chain Fixed Charge Sulfonium Ion Containing Peptides. J. Am. Soc. Mass Spectrom. 2006, 17, 1631-1642.

18. Reid, G. E.; Roberts, K. D.; Simpson, R. J.; O’Hair, R. A. J. Selective Identification and Quantitative Analysis of Methionine Containing Peptides by Charge Derivatization and Tandem Mass Spectrometry. J. Am. Soc. Mass Spectrom. 2005, 16, 1131-1150.

19. Lu, Y.; Tanasova, M.; Borhan, B.; Reid, G. E. Ionic Reagent for Controlling the Gas-Phase Fragmentation Reactions of Cross-Linked Peptides. Anal. Chem. 2008, 80, 9279-9287.

20. Frisch, M. J.; Trucks, G. W.; Schlegel, H. B.; Scuseria, G. E.; Robb, M. A Cheeseman, J. R.; Montgomery, J. A. Jr.,.; Vreven, T.; Kudin, K. N.; Burant, J. C.; Millam, J. M.; Iyengar, S. S.; Tomasi, J.; Barone, V.; Mennucci, B.; Cossi, M.; Scalmani, G.; Rega, N.; Petersson, G. A.; Nakatsuji, H.; Hada M.; Ehara, M.; Toyota, K.; Fukuda, R.; Hasegawa, J.; Ishida, M.; Nakajima, T.; Honda, Y.; Kitao, O.; Nakai, H.; Klene, M.; Li, X.; Knox, J. E.; Hratchian, H. P.; Cross, J. B.; Bakken, V.; Adamo, C.; Jaramillo, J.; Gomperts, R.; Stratmann, R. E.; Yazyev, O.; Austin, A. J.; Cammi, R.; Pomelli, C.; Ochterski, J. W.; Ayala, P. Y.; Morokuma, K.; Voth, G. A.; Salvador, P.; Dannenberg, J. J.; Zakrzewski, V. G.; Dapprich, S.; Daniels, A. D.; Strain, M. C.; Farkas, O.; Malick, D. K.; Rabuck, A. D.; Raghavachari, K.; Foresman, J. B.; Ortiz, J. V.; Cui, Q.; Baboul, A. G.; Clifford, S. Cioslowski, J.; Stefanov, B. B.; Liu, G.; Liashenko, A.; Piskorz, P.; Komaromi, I.; Martin, R. L.; Fox, D. J.; Keith, T.; Al-Laham, M. A.; Peng C. Y.; Nanayakkara, A.; Challacombe, M.; Gill, P. M. W.; Johnson, B. Chen, W.; Wong, M. W.; Gonzalez, C.; Pople, J. A. Gaussian 03, Revision C. 02, Gaussian, Inc.: Wallingford, CT, 2004.

21. Katritzky, A. R.; Watson, C. H.; Dega-Szafran, Z.; Eyler, J. R. Collisionally Activated Dissociation of N-Alkylpyridinium Cations to Pyridine and Alkyl Cations in the Gas Phase. J. Am. Chem. Soc. 1990, 112, 2471-2478.

22. Wu, Z.; Fenselau, C. Proton Affinity of Arginine Measured by the Kinetic Approach. Rapid Commun. Mass Spectrom. 1992, 6, 403-405.

23. Hiraoka, K. Relationship Between Gas-Phase Proton Affinities of Conjugate Bases B's and Free Energies of Hydration of Conjugate Acid

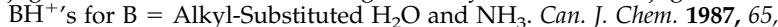
$1258-1261$.

24. Bowen, R. D.; Harrison, A. G.; Reiner, E. J. Ion-Dipole Complexes in the Unimolecular Reactions of Isolated Organic Ions. Effect of N-Methylation on Olefin and Amine Loss from Protonated Aliphatic Amines. J. Chem. Soc. Perkin Trans. II 1988, 2, 1009-1013.

25. Katritzky, A. R.; Watson, C. H.; Dega-Szafran, Z.; Eyler, J. R. Collisionally Activated Dissociation of N-Alkylpyridinium Cations to Pyridinium Cation and Olefins in the Gas Phase. J. Am. Chem. Soc. 1990, 112, 2479-2484.

26. Anders, E.; Koch, R.; Katritzky, A. R.; Malhotra, N.; Eyler, J. R.; Zimmerman, J. A. Collisionally Activated Dissociation of Some Bulky Substituted Pyridinium Cations, Substituent Effect on Appearance Potential. Chem. Ber. 1992, 125, 177-181.

27. Zins, E.; Rondeau, D.; Karoyan, P.; Fosse, C.; Rochut, S.; Pepe, C. Investigations of the Fragmentation Pathways of Benzylpyridinium Ions Under ESI/MS Conditions. J. Mass Spectrom. 2009, 44, 1668-1675.

28. Csonka, I. P.; Paizs, B.; Lendvay, G.; Suhai, S. Proton Mobility and Main Fragmentation Pathways of Protonated Glycylglycine. Rapid Commun. Mass Spectrom. 2001, 15, 1457-1472.

29. Bleiholder, C.; Paizs, B. Competing Gas-Phase Fragmentation Pathways of Asparagine-, Glutamine-, and Lysine-Containing Dipeptides. Theor. Chem. Acc. 2010, 125, 387-396.

30. Paizs, B.; Suhai, S. Towards Understanding the Tandem Mass Spectra of Protonated Oligopeptides. 1. Mechanism of Amide Bond Cleavage. J. Am. Soc. Mass Spectrom. 2004, 15, 103-113. 